'Talking the Talk' - Practical and Academic Self-Concepts of Early Years

\title{
Practitioners in England
}

Wendy Sims-Schouten and Helga Stittrich-Lyons

University of Portsmouth

\begin{abstract}
Traditionally the status of workers in early childhood services in England has been low. Foundation degrees and the Early Years Professional Status (EYPS, from September 2013 Early Years Teacher Status) were established with a view to improving the skills and standing of early years practitioners. There appears however to be an ongoing discrepancy between practitioners' positive commitment to their professional development and the continued focus on the fact that they are somehow lacking and in need of transformation. This paper explores practical and academic self-concepts of early years practitioners, and its association with academic achievement and wider societal perspectives. Individual interviews $(n=10)$ and three focus group discussions with early years foundation degree students were analysed using a form of discursive psychology. In their arguing and thinking the practitioners within their selfconceptualizations showed evidence of a transition between two overall identities, one related to their 'practical identity' and one related to their 'educated early years practitioner identity'.
\end{abstract}

Keywords: early years practitioners; academic self-concept; social influence; identity; empowering

Infant development is conceptualized as embedded within emergent active systems of relationships (Thomasgard, Warfield and Williams 2004). Hence, the social, emotional and cognitive development of infants is linked to the various contexts within which care giving takes place. Of these 'contexts', daycare has been reviewed with emphasis placed on the qualifications of early years practitioners. The EPPE project (Effective Provision of Pre-school Education), a longitudinal study of childcare in Britain which took place between 1997-2003, advised the then Labour government to characterise and promote young children's learning concluding that the qualifications of early years 
practitioners were key here (Siraj-Blatchford 2009; Sylva et al 2007, 2010). Taking a slightly different approach, the REPEY (Researching Effective Pedagogy in Early Years), a collaborative research project which was commissioned by the UK Department for Education and Skills, explored factors linked to effective practice, describing professional and personal qualities such as knowledge and values as elements of good early years practitioners (Siraj-Blatchford et al 2002).

Between 1997 and 2010, the then Labour-government had an increased focus on raising the qualifications of the workforce and the related status of practitioners working with young children. Considerable progress was achieved during this Labour- tenure, funding was made available for early years workers who wanted to embark on Higher Education $(\mathrm{HE})$, therein improving their knowledge, expertise and motivation when it comes to working with children. The overarching trend was towards a HE system that provides a population that is work-ready with professional and technical skills that meet the Government's demands in a global and technical advanced economy (DfES 2003). Workforce analyses have indicated particular problems in the under-education at the technician - senior practitioner level (DfES 2003). These problems are not unique to England but can also be recognised within the German and the French HE systems. Foundation Degrees (FD) in early years and the Early Years Professional Status were established, with a view to develop a workforce to be '...led by well-skilled and highly motivated individuals' (Osgood 2009, 743). Foundation Degrees are not however purely servants of business. Although there is a strong emphasis on work-based learning (WBL) and competency, it is practical training that is integrated with academic study which includes reflective learning as well as the accreditation of prior experiential learning (APEL).

"Work-based learning is the term being used to describe a class of 
university programmes that bring together universities and work organisations to create new learning opportunities in workplaces." (Boud and Solomon 2001, 4)

The involvement of employers was seen as vital to success and the overall goal was to raise the standards and status of childcare and their workers in Britain beyond the focus on targets and statements, which is the approach taken by the competence-based and work-related National Vocational Qualifications. Following Nutbrown (2012), the complexities of children's development, minds, bodies and emotions must never be reduced to a set of simplistic targets and statements. In addition to this, Foundation Degrees early years were seen as key in improving social inclusion, skills acquisition and longer term social and economic prosperity (Kendall, Carey and Cramp 2012). The focus here was on a development that specifically addresses the Senior Practitioner issue and emphasises widening participation, new modes of study and the growing diversity of learning styles, including work-based and reflective methods. Whilst the FD in early years provided a new level of professional practice (Senior Practitioner Status), it also offered a route to graduate status, the Early Years Professional Status (EYPS). Findings from a study by Hadfield et al (2010) highlight the positive impact of Early Years Professional Status in supporting workforce development across the early years sector. Yet, this improvement does not appear to be replicated in the attitudes of other professions or groups. The introduction of the Early Years Professional (EYP) role raised many issues, such as the lack of parity of their status in relation to qualified teachers, and the lack of guidance on commensurate levels of pay (Nutbrown 2012). For example, while EYPs were initially heralded as having equivalent status to teachers, the current position seems to be that qualified teachers still take the lead in settings maintained by local authorities (i.e. nursery schools and schools), whilst EYPs will be restricted to the private and voluntary sector. Additionally, levels of pay are set out and agreed for 
teachers, but for EYPs, they are left to market forces (Miller 2008). From September 2013 the EYP will be replaced by the EYT (Early Years Teacher). Following Nutbrown (2012), a focus on 'Early Years Teacher' as opposed to 'Early Years Professional' builds on the EYP route and is focused on building more of a parity with teachers, as well as increasing professionalism and improving quality. However, many early years workers question whether the change will lead to increased pay and professional recognition especially as EYTs will - like EYPs - not have Qualified Teacher Status (QTS), meaning that they will not be entitled to the same pay and conditions as other teachers. As such, since the introduction of the Foundation Degree in early years many issues remain unresolved, including lack of pay and recognition for the role in the workplace, and more recently the relationship of this role to the Early Years Professional (EYP) and the Early Years Teacher (EYT) role described above.

The key education policies set in motion by the current UK coalition government (Conservative/Liberal coalition) continue to focus on improving structures and qualifications, apprenticeship opportunities, improving access to higher education, access to internships, access to professions, wage progression of low earners and second chances for adults to gain qualifications. The free 15 hours childcare for the most disadvantaged $20 \%$ of families (by 2013 to reach $40 \%$ by 2014 ) requires EY professionals that are skilled and trained (DfE 2012). The government pledges its commitment to "ensure that children receive high quality early education (ibid), this includes having a highly qualified workforce (ibid), although they don't stipulate how practitioners are to achieve this. Having said this, they promise to "improve the skills of the existing workforce in disadvantaged areas, ... including New Leaders in Early Years",... "ensuring graduate leadership" ... an updated Early Years Professional Status 
programme, which makes improving the skills of professionals who work in disadvantaged areas a specific priority"(ibid).

As such, reforming the workforce through a programme of training and qualifications was and is seen as crucial in raising the quality of services. So, as Osgood $(2009,736)$ suggests 'the nursery worker must rise to the childcare challenge'. However, following Nutbrown $(2012,4)$, it is still the case that working in the early years is too often seen as a low level job which involves, as some have expressed, 'wiping noses' and 'playing with kids', and it is not necessarily regarded as a professional occupation that demands good qualifications and expertise. Yet, whilst the status of the early years workforce might be low, this does not mean that early years practitioners are less capable compared with teachers when it comes to supporting young children in their learning. In their study on patterns of interaction between pupils and a range of adults (such as teachers, parents and nursery nurses) in early-years classrooms Hughes and Westgate (2004) found that nursery nurses created more diverse opportunities, compared with teachers, who appeared to be quite consistent but limiting in their approach, giving pupils access to relatively few communicative roles other than that of respondents. In addition to this, research shows that early years professionals are able to influence change and positively affect outcome for children against all five areas of the Every Child Matters change for children initiatives of being healthy, staying safe, enjoying and achieving, making a positive contribution and achieving economic well-being (Davis and Barry 2013).

What practitioners need, following Fleer, Anning and Cullen $(2009,189)$ is a 'language to share their reflections in spoken and written versions'. Here it is also important to take the training, personal histories and beliefs of early years practitioners into account, as it 
is the belief that practitioners hold about their capabilities that makes the difference between success and failure (Klassen \& Usher 2010). This paper will explore multifaceted and hierarchically organised self-concepts of early years pracitioners, taking the starting point that self-concept is closely associated with people's behaviour and academic achievement (Marsh and Martin 2011). With the arrival of FDs many vocational/academic courses were launched in $\mathrm{HE}$, often with little or no knowledge about what this would mean in real teaching and learning terms, for both the students and the academics. Higher Education Institutions (HEls), although associated and experienced with issues of learning and teaching, had nothing or little to do with subprofessional vocational training (the hands-on technical side of work), work-based learning and or employer involvement except in for example the areas of teacher training, and the health field. As such Higher Education Institutions (HEIs), had relatively little experience of issues relating to this developing workforce, their training traditions and the work-based learning and employer involvement expected of Foundation degrees. In addition to this there were issues around the recognition of the FD (Herrera, Brown and Portlock 2013). An added problem was that FDs in early years were attracting students with often-negative self-concepts in relation to their academic abilities, not least due to the low status of their profession "I am only a nursery nurse" (anecdotal: level 4 trained EY practitioner). The so-called 'Golem effect', which is based on the Hebrew word for dumbbell referring to the fact that when we expect little of others, we provide negative, inferior or indifferent treatment and ultimately receive little in return (Babad, Inbar and Rosenthal 1982; Weinstein 2002).

\section{Practical and Academic Self-Concept}


Self-concept is closely associated with cognitive and emotional outcomes, people's selfesteem and academic achievement (Marsh and Martin 2011). In addition to this, Marsh (2007) argues that prior academic self-concept and subsequent achievements are strongly linked (see also Urhahne, Chao, Florineth, Luttenberger and Paechter 2011). As such, self-concept enhancement is a crucial goal in education, and an important instrument for addressing social inequalities (Marsh and Martin 2011). Foundation Degrees were established to provide academic enrichment, increase self-confidence and understanding of working practices through widening participation and social inclusion. The success of these programmes and commitment to improvement in qualifications of the Early Years (EY) workforce can in part be measured by the extent to which they have transformed or have empowered the EY work force and raised their status. Empowerment has been conceptualised as a narrative of self-transgression as in efficacy theory (e.g. see Bandura, although he refers to 'abilities' as opposed to empowerment), which understands empowerment as a set of beliefs about the self in relation to specific activities (Drury, Cocking, Beale, Hanson and Rapley 2005).

Despite the recent focus on early years professional development (i.e. through raising the qualifications of the early years workforce), research shows there remains a discrepancy between practitioners' positive commitment to their own professional development (Mahadevan 2011), and the continued focus on the fact that they are somehow lacking and still in need of transformation (Allen 2011; Osgood 2009). For example, the Graham Allen (MP) report on early intervention, focused on the quality of the early years workforce, and concludes:

We must, therefore, ensure that all those working with children are adequately trained and I am aware that standards currently need to be raised (Allen, 2011, 56). 
According to Bandura (1997) individuals' interpretations of their mastery experiences or previous successful experiences are crucial factors associated with educational success, whereas failure experiences undermine people's self-efficacy. It could be argued that with the continuing perception of low status of early years practitioners, a form of collective efficacy is at play here. Collective efficacy is a group's shared beliefs about its capabilities to carry out a desired course of action (Klassen and Usher 2010). For example, as one early years practitioner once said: 'we are just childminders, that is all we are, we are not very academic'. These beliefs and self-concepts have their origins in our social interactions with other persons and society at large (Martin 2010). It is the authors' argument in relation to EY education that although skills and knowledge provide the tools for success within educational settings, it is the beliefs the students (and others) hold about their capabilities to use these tools that ultimately counts. Yet, although as stated earlier on, a lot has been achieved by the English government in terms of creating opportunities and making funding available for early years workers to embark on a degree, the question is whether this has raised their status and empowered them. Here, to an extent self-efficacy (the confidence that one has in one's abilities) and self esteem (a judgement of one's own personal and social value) cross over.

\section{Aims and Methodology}

In this paper we explore the self-concepts of early years practitioners. Our focus lies on practitioners' (i.e. people working in early years settings) constructions of themselves, their professionality and identities in relation to them undertaking Foundation Degrees in Early Years Care and Education at University. In this paper we focus on FDs, a development that specifically addresses the Senior Practitioner issue and emphasises widening participation, new modes of study and the growing diversity of learning styles, including WBL and reflections, designed to breaking down barriers and to be all- 
inclusive. In England qualified teachers working in early years settings have long enjoyed the sense that they are regarded as professionals, whereas others working with young children have not (Miller 2008). Yet, according to Nutbrown $(2012,5)$ the sector is becoming more professional. Here Nutbrown refers to the fact that early years carers and educators are professionals who need to be able, continually, to develop their knowledge, skills and understanding, as well as being confident in their practice. The development of a more professional workforce through the reform process described earlier has been generally welcomed by those who have been working to raise the status of early years practitioners and help them achieve a sense of professional identity (Miller 2008). Yet, within this there is the danger that this emphasis on 'professionalism and professionalisation' (through a focus on goals, standards and making practice measurable) in England threatens the empowerment of the early years workforce by inhibiting professional autonomy. In addition to this, there is a sense that a managerial construction of 'professionalism' runs counter to the emotional nature of early years work (Osgood 2006). Thus, defining professionalism in the early years workforce is the subject of much debate, and there is a need to recognise the complexity of professional identity.

In-depth individual interviews (10) and focus group discussions (3) with Early Years Foundation Degree students were analyzed drawing on discursive psychology as a methodological framework (Edwards 1997; Hepburn and Wiggins 2007; Potter and Wetherell 1999). Discursive psychology is grounded in a social constructionist approach, which applies ideas from discourse analysis to psychological issues and concepts (Sims-Schouten, Riley and Willig 2007; Speer and Potter 2000). For discursive psychologists, what people say is not taken to represent the contents of their mind, what they are thinking or 'reality'; instead, mind and reality are first and foremost resources for 
people in dialogue (Hepburn and Wiggins 2007). As such, the core principles of discursive psychology are that talk is action orientated, sequential, rhetorical, constructed and constructive (Potter and Edwards 2001). Discursive psychologists thus focus on text to study its effects interactionally. Key analytics are accountability, stake and interest, and how people draw on psychological concepts such as social identity, so that transcripts of talk are analysed in terms of how participants deal with and position these aspects in ways that achieve certain interactional effects, for example, avoiding blame (see also Riley 2003; Wiggins and Riley 2010). For our purposes interviews were an appropriate method to collate early years practitioners' accounts of themselves and their practical and academic self-concepts, but we note that traditional discursive psychologists argue for what they call 'naturally occurring talk', talk that would have occurred if the research project had not existed (see also Sims-Schouten and Riley, forthcoming). Research indicates that professional identity in early years is often derived from status through qualifications and knowledge base and the respect and confidence that comes with this (Miller 2008; Osgood 2009). This raises questions regarding the self-concepts and identities for practitioners, during and after embarking on their FD in Early Years Care and Education. FDs were established to provide academic enrichment, increased self-confidence and understanding of working practices through widening participation and social inclusion. Nutbrown (2012) talks about 'theoretical knowledge' and 'practical experience' when discussing qualifications, content and process of the early years workforce. Reflection on practice is recognised as an important component in developing professional and pedagogical knowledge and in understanding practice (Miller 2008). This raises questions regarding the multifaceted and hierchically organised self-concepts of early years workers. As can be seen from the analysis below, participants frequently referred to their practical abilities in relation to working with children, and their academic abilities in relation to academic study and knowledge 
tranfer. As such the specific focus here will be on the participants' talk in relation to their practice-based and academical self-concepts. All participants were early years practitioners, some were employed in nurseries, whilst other were childminders.

Discursive psychology draws on conversation analysis's fundamental reconception of discourse as action, not communication (Edwards 1997). As said above, we take the stance that talk is action oriented, situated (sequentially, institutionally and rhetorically), constructed and constructive. As such we would expect that in their talk in relation to their work and HE identities, participants will draw on different versions of actions, events and social structures. Here the focus lies on mind and reality as a resource for participants in dialogue, not as something we have or we are, but as resources for action. However, self-beliefs are not without contradiction, within their discourse persons as speakers shift from one stance to another when talking about themselves and their position (Billig 2001). Once having a taken up a particular position as one's own, a person inevitably constructs their world and themselves within this from the vantage point of that position (Davies and Harre 2001). Here talk is situated and managed within broader practices and constructions. For example, Osgood $(2009,737)$ found that:

Governmental discourse is laden with classed and gendered notions about who should enter the childcare workforce: those with spare time on their hands but lacking educational and social capital to gain 'real' employment.

Below we will discuss how the participants conceptualized themselves in relation to their work/professional and HE identities, and how they negotiate the transition between the two. Interviews are transcribed in detail, following Jefferson (1985), and an adaptation from Edwards (1997) and Ten Have (1999), see Appendix 1.

\section{'I am Just an early years practitioner’ - High Expectations versus Low Status}


In their arguing and thinking the practitioners within their self-conceptualisations showed evidence of a transition between two overall identities, one which was related to their practice, which we will call their 'practical' identity and one that was related to their HE study, which we will call the 'educated early years practitioner'. Both are professional, yet in different ways. The participants conceptualised their practical identity in terms of 'working with children', i.e. that this is something that they do and are good at. The 'educated early years practitioner' identity was constructed in terms of 'being a professional', 'talking to parents'. The issue of confidence (both in positive and negative terms) was uttered in relation to both identities. The first extract comes from a focus group discussion.

1. W: How do you f:eel about doing a foundation degree in general?

2. A: Me, erm, basically, I started out of interest, erm. I didn't, didn't, I >never had

3. any relevant experience $<$. So. hh, I just wanted to $>$ see what it was all

4. about<. But .hh, now I kind of feel that, erm (..), in our job, although it he:Ips

5. us, cause >we're only< we're childminders, it helps us to work better with the

6. children, ! think. But the parents still perceive you as >exactly the same

7. person as you were then<

8. W: Really

9. A : Yeah

10. W: [So,

11. A : [There's no, they don't see you any better now then you were two years ago.

12. even though .hh, yeah, the children obviously, you're doing er, you maybe

13. have more kno:wledge, [they

14. S, P: $\quad$ [\{mumbling and laughter $\}$ 
15. A :

[The children have benefited, but the parents still see

16. you as just a childminder they drop their children off to.

Participant $A$ in the extract above starts her answer in relation to why she is doing a Foundation Degree by focusing on her personal stake (Pomerantz 1986), where her key argument of starting the degree 'out of interest' (line 2) is followed by the quickly uttered argument that she >never had any relevant experience< (lines 2, 3), after which the argument that she just wanted to see what it was all about is repeated. So, doing the degree is firmly constructed as something this participant decided to do, i.e. there was an element of choice in her decision. This is supported by her utterance that she never had any relevant experience, which is said very quickly (indicated by $><$ ), almost as a matter of fact, as an aside. Her focus on 'personal interest and choice' is significant in the light of the previously discussed governmental requirements and guidelines when it comes to educating the early years workforce (see also Osgood 2009). In other words, although the foundation degree is part of the government's plan to improve and motivate the early years workforce, this participant shows that what motivated her was to >see what it was all about< (lines 3,4$)$. Yet, the fact that she cannot escape the lack of status (Anning, 2009) and 'crisis' (Osgood 2009) attached to early years in the England is evident from what sounds almost like a disclaimer (Speer and Potter 2000) in line 4 “ 'But .hh now I kind of feel that, erm (..), in our job...'. This is also evident in the selfrepair (Speer \& Potter 2000) in line 5 '>we're only< we're childminders'. In other words, this participant is trying to head off the attribution that she might be 'lacking' and 'in need of improvement', because she is 'only' a childminder. As such, through undertaking her HE degree she has gained more experience when it comes to working with children (it helps us to work better with the children, line 5). Note how she moves from talking in the first person in the first bit, when she refers to starting the degree out of interest, to talking 
about 'us', about childminders as a collective group and collective efficacy, when talking about working better with children. At the same time she indicates that this (i.e. her HE degree and improvement in working with children) has not led to different treatment from the parents of the children that she is looking after: 'But the parents still perceive you as >exactly the same person as you were then< (lines 6,7$)$ '. This low status of early years practitioners is also addressed earlier on in this paper. This participant's talk suggests that although her undertaking a degree has helped her work better with children, it has not led to an increase in status, she is still 'exactly the same person', she is still 'just a childminder' (line 16). This depreciatory positioning can be directly linked to Osgood's (2009) analysis of the early years practitioner in policy discourse, which implies that she is in need of transformation. Lloyd and Hallet (2010) argue that the process of professionalising the early years workforce is a work in progress. Yet, in more than one way, as can be seen from the extract above. This is evident from the fact that although the degree leads to an improvement in this participant's perception of her ability to work with children, it does not lead to an increase in status, as 'they don't see you any better now then you were two years ago' (line 11). This is followed by mumbling and laughter in agreement from other participants in the focus group. Billig (1992) argues that people in their arguing and thinking are contradictory, shifting from one way of thinking to another. This is evident from the fact that participant $A$, in the extract above, voices different reasons for embarking on a foundation degree in early years. She has started the degree 'out of interest', as well as having no relevant experience (lines 1-3). Yet, there appears to be a discrepancy between her reasons for doing the degree and the perceived outcomes. From the reasons for why the participant started the degree ('interest' and 'lack of experience') the outcome of working better with children (lines 5, 6) could have been perceived ideal. This is supported by the EPPE study (Sylva et al 2010), which reflected a link between improved qualifications of the early years 
workforce and quality of care that children receive in daycare settings. Yet, it looks like this was only one of the envisaged or hoped for outcomes for the participant in the extract above, which is evident from the disclaimer 'The children have benefited, but the parents still see you as just a childminder they drop their children off to' (lines 15,16$)$. So, although doing the early years degree has led to an improvement in practice, it has not led to an increase in respect and status. The children may have benefited, but the practitioner still needs the acknowledgment and respect from the adults surrounding the child, as self-status beliefs that early years workers hold are very much linked to social interactions with other persons and society at large (Martin 2010). The extract above shows that 'being a professional' (and being acknowledged as such) is an important part of the 'educated early years practitioner' identity.

\section{Working with children and Talking with Parents}

The next extract comes from a focus group and is part of a discussion about 'change' and that undertaking the FD Early Years degree has led to changes in the way the participants were dealing with parents. Contradicting self-concepts in relation to the ability to 'work with children' and 'talk to parents' were uttered time and time again in the interviews.

1. $\mathrm{H}$ : > I have always been a very confident person<(1.0). .hh But in this particular

2. field, erm I believed I had a huge mountain to climb, and I think I climbed quite

3. a way up it. But as I began to climb up this mountain of knowledge, .hh

4. associated with the early years, I think it has manifested itself in my dealing

5. with parents, >as opposed to how I deal with the children<, ermm because I

6. think I always dealt well with the children. 


\section{W: [Right}

8. H: [Perhaps I can now verbalise it better and write better about it, er but I

9. actually think I always did that, but just now I think I can transfer or translate

10. that information across to the parent better.

Above is an example of a participant who is making a link between her dealings with parents prior to and after undertaking an early years degree. This participant starts off by positioning herself as a confident person: ' $>$ I have always been a very confident person<' (line 1), which is brought up as a matter of fact. By arguing that she is a confident person she shows that whatever problems she encountered whilst doing her degree cannot be reduced to her self-esteem, as her self-esteem has 'always' (line 1) been good. Here she uses a disclaimer (Speer and Potter 2000) (line 1, signified by the 'But in this particular field...') arguing, that she is a confident person, but was challenged by the particular field in which she found herself in (i.e. undertaking an early years qualification). This argument is strengthened through the use of a metaphor in which she compares undertaking her degree with climbing a mountain. Here the participant makes it very clear that prior to undertaking her degree she might have been lacking in her ability to 'transfer or translate that information across to the parent' (lines 9,10 ), yet, she was not lacking in her ability to work with children: 'I think I always dealt well with the children' (lines 5,6), putting emphasis on the word 'well' to show that there is no doubt here. The latter is a 'concession marker' (Antaki and Wetherell 1999) that shows (through the emphasis on 'well') that she has considerable ability in child work, and is significant in relation to the government's continued focus on 'ensuring that children receive high quality early education' through 'having a high quality workforce' (DfE 2012). Again, she is bolstering against any doubt, by constructing this as something that comes from her personal practice in relation to her own past work with children. So, in 
the transition from one identity to another, i.e. the 'practical practitioner' to the 'HE educated practitioner', this participant shows how her ability to work with children has now been strengthened by her improved skill to translate and transfer this information to the parents. As such, working with children and talking to parents are constructed as two very different skills.

A further respondent suggests that in relation to parents her confidence and professionalism have grown as a result of her FD studies, as can be seen in the seen in the extract below:

1. P: I am a childminder

2. W: $\left[{ }^{\circ}\right.$ yeah $^{\circ}$

3. P: [When parents contact me, .hh and I tell them $>$ I don't want them Friday<,

4. because l'm doing (..) the foundation degree, (1.0) a number of parents have

5. said that's why they come to see me first. And I am actually full now. ${ }^{\circ}$ cant $^{\circ}$

6. and I suspect that that the professionalism is err, why parents ${ }^{\circ}$ would then

7. come and look at $\mathrm{me}^{\circ}$. And also the way I speak to parents (..) l'm more, a bit

8. more knowledg >oh, obviously a lot more $<$ knowledgeable, so the way !

9. speak to them is slightly different, so:: then their response to me will be

10. different.

The participant in this extract links her 'professionalism' directly to 'the foundation degree' (line 4), and this argument that her undertaking a foundation degree has helped her in her professional development is further supported by what Riley (2003) calls 'a sandwich argument'. Here, the key argument 'the way I speak to parents' (line 7), is followed by the argument '>oh, obviously a lot more< knowledgeable' (line 8), after 
which the participant returns to her key argument 'the way I speak to them' (lines 8, 9). Here it is interesting to see how the participant constructs herself as being '>obviously a lot more< knowledgeable' (which is the self-repair that follows her utterance of being 'a bit more knowledg' in lines 7,8$)$, which has an impact on how she speaks to parents, which she constructs as being 'slightly different' (line 9). So why does she not engage in self-repair when talking about how she speaks to parents, i.e. why does she not say that the way she speaks to parents a 'a lot' or 'totally' different? One explanation for this could be that talking about knowledge and improved knowledge is relatively safe, i.e. as people we learn things, which increases our knowledge. However, the issue of how she speaks to parents is different, as here she is reflecting on her person, and her abilities to put things across to other adults, by referring to 'slightly' instead of 'a lot' she shows that the way she talked to parents prior to doing the degree was not 'bad' it was just slightly different. This does not change the fact that for this participant her improvement in skills and qualifications has resulted in raising her status as an early years practitioner. Osgood (2009) also refers to this process in her analysis of political discourse and constructions in relation to improved qualifications of early years practitioners. The participant in the extract above indicates that she is able to 'talk the talk' ('the way I speak', line 8) leading to a different (improved) response from parents.

\section{Confidence and empowerment through study}

The issue of 'confidence' was addressed in many of the interviews: in relation to talking to parents; in relation to 'being a professional' but more fundamentally in relation to educational self-worth, as one early year practitioner student indicated 'I wasn't very good at school, so I had a choice, it was either going to be hairdressing or a nursery, 
and it became the latter'. The extract below comes from an individual interview and illustrates this latter point in relation to intellectual growth.

1. $\mathrm{N}$ : I feel that it is err that stepping stone to update your knowledge

2. >but also bring you up to date< with like the EYFS*, but give you that err

3. confidence to actually er $>$ Early Years is such a big thing now $<$, erm that actually

4. eh yeah it is really good to actually know all these different things and to put

5. these different things into practice, $>$ but to also whilst you are doing that $<$ to be

6. able to also put it into an assignment[

7. W :

[yeah

8. $\mathrm{N}$ : to er put that reflection on your practice is really good.

*The EYFS or Early Years Foundation Stage is the English equivalent of a curriculum for the early years. Further information can be found on the Department for Education website: https://www.education.gov.uk/publications/standard/AllPublications/Page1/DFE00023-2012

This participant constructs her degree in early years as a 'stepping stone to update your knowledge' (line 1). Here 'stepping stone' refers to the development of knowledge and progression in knowledge and understanding, which is brought about by her HE degree studies. Further, she suggests that this will not only bring 'you up to date', but will also 'give you that confidence', emphasizing the word 'confidence'. The word 'that' and stress on 'confidence' suggests confidence is automatically linked to undertaking a degree, just like the other factors that she mentions, namely 'to update your knowledge' (line 1) and be able to put 'into practice' (line 5) and into academic study itself, and putting 'it into an assignment' (line 6). Her comment that 'Early years is such a big thing now' is used to strengthen her argument and incorporates 'political discourse' through her reference to the state of affairs brought about by political and policy changes encapsulated in the Early Years Foundation Stage (EYFS) curriculum (DCSF 2008; DfE 2012). Osgood 
(2009) points to the government's vision of the nursery worker as the guardian of the nation's children. An interesting point here is how in the extract above the 'update of knowledge' is constructed in terms of not just benefiting practice, but also the confidence and self-concept of the person involved. Evidence of this can also be seen in the literature (Anning 2009; Dean 2005; Osgood 2009).

The participant in the extract below also raises the issues of 'growing as a person' and 'confidence' in explaining how her HE degree affected her:

1. W: How do you feel about your abilities after, after having done it [the foundation

2. degree], (1.0). Pretty much, you are pretty much finished now aren't you?]

3. $P$ : Yeah],

4. erm (..), I think its its, you know ${ }^{\circ}$ not only helping the practice ${ }^{\circ}$, bu::t it has

5. made me grow as a person in terms of confidence, and you know, er (..), sort

6. of the way I approach anything written now, its helped that.

This participant uses a three-way-list completer in her discussion of how the foundation degree has helped her improve her abilities (Antaki \& Wetherell 1999). This shows the importance of her doing the degree: for 'helping practice' (line 4), and 'made her grow as a person in terms of confidence' (line 5), as well as 'the way I approach anything written now' (line 6). So, this participant indicates that doing the degree has helped her gain educational (helping practice and the way she approaches anything written) and social capital (confidence). The educational benefits of undertaking a University degree in early years are also evident from the extract below:

1. W: What is it, what has it [doing a foundation degree] erm, done to you 
2. professionally?

3. P: Mine was twofold really, was, firstly I er wanted a personal challenge

4. W: yeah]

5. P: and I do like academic and learning and I never feel I know enough, and erm, I

6. always feel I need to know more, so, the learning there::fore has given me:: a lot

7. more confidence and lingered on my self-esteem that when I'm speaking to

8. parents .hh or er working with other practitioners, or in a group within the

9. children's information service I felt more confident because I have that

10. knowledge which is quite empowering. The second reason is, er, a setting needs

11. a professional, someone with professional status (..) so:, obviously being in the

12. management position, I need to lead my team, so I need to be seen to be doing

13. learning and taking qualifications, thus its, erm my fellow staff feel if the manager

14. is doing it, it is actually empowering them to do it.

Here, the participant refers to a personal character trait when she says that she always feels she needs to know more (lines 5 and 6). This personal stake orientation (Potter 1997) serves to strengthen her argument by making it personal (i.e. it cannot be disputed as she is referring to herself here). In addition to this, she is repeating this personal trait three times: "I do like academic and learning" (line 5), 'I never feel I know enough' (line 5), and 'I always feel I need to know more' (line 6). Again, educational and personal gains are directly linked, as the participant makes a direct link between her increase in knowledge and her self-esteem (line 7), which is summarized by the emphasis on the word 'empowering' (line 10). Note that 'confidence' (line 7) and 'speaking to parents' (line 7, 8) and others (lines 8, 9) are directly linked in this participant's speech. For far too long has the early years workforce had to suffer from 
low status and gendered and classed notions about what comprises this workforce (see also Anning 2009, Dean 2005; Osgood 2009). This has had an impact on their selfconcept, especially in relation to their professional and academic skills ('Talking the Talk') as early years practitioners. The low status of the early years workforce has led early years practitioners to construct their identity in terms of confidence and selfesteem, even in the case of the participant who argued that she has always been a confident person (referring to confidence here makes it an issue in itself). At the same time, the Governmental requirements for improvement in education bring with them an increase in confidence, knowledge and self-esteem amongst the practitioners who are partaking in this. Yet, in the extract above the Governmental requirement to 'be seen to be doing learning and taking qualifications' (line 12,13) is uttered as this participant's second reason for doing the degree, and something that empowers not just her, but also her staff (lines 13, 14). As such, the personal choice and challenge of undertaking the degree is constructed as empowering the participant, whereas the 'requirement' to do this serves to empower fellow staff.

\section{Conclusion}

It could be argued that the goal to create an early years workforce led by 'well-skilled and highly motivated individuals' (Osgood 2009, 743) has been achieved to an extent through the creation of Foundation Degrees (and the Early Years Professional Status, from September 2013 the Early Years Teacher Status). The findings show that 'belief' systems and wider power structures in relation to early years practitioners' skills and abilities are also evident in their Talk. Participants in the interviews made clear distinctions between their abilities prior to and whilst embarking on their degree. Confidence and 'talking the talk' were key here. Yet, the Government's continued focus 
on their lack of skill and motivation prior to doing the course, also appears to have taken its toll, as participants were often very defensive in their talk of their abilities when it comes to working with children - something they indicated they were good at, prior to embarking on the degree. The Government negates this by consistently emphasising the link between qualifications for the early years workforce and high quality early years care and education. Discursive psychology examines accounts, the idea being that descriptions and accounts constitute the nature of events, and set it up descriptively as some kind of problem to be solved, something that calls for one or another kind of explanation, and which may contain already, within the description, the seeds or implications of explanation (Edwards 1997, 13). For example, participants frequently referred to themselves, as being just childminders or just working with children, indicating a gap between their practical and academic identities. At the same time, the participants constructed their HE study in terms of 'empowering' and leading to increased confidence. As discussed earlier on, research indicates that professional identity in early years is often derived from status through qualifications and knowledge base and the respect and confidence that comes with this (Miller 2008; Osgood 2009).

Yet, it could be argued that early years practitioners are professionals by default (regardless of undertaking a HE degree). For example Hughes and Westgate (2004) found that early years practitioners are very able when it comes to creating diverse opportunities for children, perhaps even more so than teachers. In addition to this, David and Barry (2013) found that early years professionals are able to influence change and positively affect outcome for children against all five areas of the Every Child Matters change for children initiatives. Nevertheless, if early years practitioners want to move forward and improve their status, then they have to know how to 'talk', how to 'sound' professional. It follows that the constant pressure on the early years workforce to 
'become educated' means that once they are embarking on a degree in early years they all too readily dismiss their prior professional knowledge and experience. As such, instead of constructing themselves as the ultimate professionals, who are in the unique position of drawing on extensive practical knowledge and experience, whilst embarking on academic study, they talk about themselves in terms of 'low confidence' and 'little knowledge'. The appreciation and apprehension with which academic study is approached, can perhaps be linked back to what one of our students once said in class: "I had a choice, to either go into hairdressing or work in a nursery - it became the latter" Here self-efficacy and self-esteem cross over. Nevertheless, early years degrees have served their goal in increasing practitioners' confidence in their dealings with parents and in gaining respect, and as such could be seen as a step closer to achieving increased status. Yet, within this it is important to not side-step the crucial role of the early years workforce in supporting children in their (social, emotional, and cognitive devevelopment), something that is also acknowledged in the Allen report (2011). As such, (increased) status and 'professionalism' should include notions, not just in relation to being an 'educated' early years practitioner, but also as one that is skilled in dealing with children. Different strands of science, such as neuroscience, evolutionary theory, and cognitive and socioemotional developmental psychology, have demonstrated that infancy is a formative phase during lifespan development (see Keller 2011 for a discussion). In addition to this, large and rapidly growing bodies of research, including extensive meta-analytic reviews, have consistently supported the links between early security and insecurity in the child's early relationships and future adaptive and maladaptive developmental outcomes (e.g. van IJzendoorn, Schuengel and BakermansKranenburg 1999). As such this study raises questions in relation to early years practitioners' status when it comes to influencing and impacting upon young children's 
psychological development. Early years practitioners have multiple identities and greater emphasis should be placed on understanding their practice, professional and academic identities. More research is needed to provide insights into ways in which connections can be formed and relationships built between parents and practitioners in early years settings, and the ways in which they (parents and practitioners) interface in defining 'quality' in early years care and education.

\section{Bibliography}

Allen, G. 2011. Early Intervention: The Next Steps. An Independent Report to Her Majesty's Government. HM Government.

Anning, A. 2009. The co-construction of and early childhood curriculum. In: Anning, A., Cullen, J., and Fleer, M. (Eds). Early Childhood Education. Society and Culture (pp. 6779). London: Sage.

Anning, A., Cullen, J., and Fleer, M. 2009. Research contexts across cultures. In: Anning, A., Cullen, J., and Fleer, M. (Eds). Early Childhood Education. Society and Culture (pp. 1-24). London: Sage.

Antaki, C., and Wetherell, M. 1999. Show Concessions. Discourse Studies. 1 (1), 7-27.

Babad, E., Inbar, J., and Rosenthal, R. 1982. Pygmalion, Galatea and the Golem: Investigations of Biased and Unbiased Teachers. Journal of Educational Psychology, 74, 459-474.

Bandura, A. 1997. Self-Efficacy: The exercise of control. New York: Freeman.

Bandura, A. 2004. Swimming against the mainstream: The early years from chilly tributary to transformative mainstream.Behaviour Research and Therapy, 42, 613-630.

Barker, C., and Galasinski, D. 2006. Cultural Studies and Discourse Analysis. A Dialogue on Language and Identity. London: Sage. 
Bembenutty, H. 2007. The last word: An Interview with Frank Pajares: God, the devil, William James, the Little Prince and self-efficacy. Journal of Advanced Academics, 18, 660-677.

Billig, M. 1992. Talking of the Royal Family. London and New York: Routledge.

Billig, M. 2001. Discursive, Rhetorical and Ideological Messages. In: Wetherell, M., Taylor, S., and Yates, S.J. (Eds.). Discourse Theory and Practice. A Reader (pp. 210222). London: Sage.

Boud, D and Solomon, N. 2001 Work-based Learning A New Higher Education? OUP.

Colloby, J. 2009. The Validation Process for EYPS. Exeter: Learning Matters.

Cullen, J, 2009. Adults co-constructing professional knowledge. In: Anning, A., Cullen, J., and Fleer, M. (Eds.). Early Childhood Education. Society and Culture (pp. 80-90). London: Sage.

Davies, B., and Harre, R. 2001. Positioning: The Discursive Production of Selves. In: Wetherell, M.; Taylor, S., and Yates, S.J. (Eds.). Discourse Theory and Practice. A Reader (pp. 261'-271). London: Sage.

Davis, G., and Barry, A. 2013. "Positive outcomes for children: Early Years Professionals effectin g change" Early Child Development and Care, Vol 183, Issue 1, 37-48.

Day, K., and Keys, T. 2008. Starving in Cyberspace: The Construction of Identity on 'Pro-eating-disorder' Websites. In: Riley, S., Burns, M., Frith, H., Wiggins, S., and Markula, P. (Eds.). Critical Bodies. Representations, Identities and Practices of Weight and Body Management (pp.81-100). Basingstoke: Palgrave Macmillan.

DCSF. 2008, Early Years Foundation Stage. Annual Reports, DCSF-01064-2008

DCSF. 2009. Measuring Progress at Pupil, School and National Levels.

Dean, E. 2005. Reform or rejection? The impact of change on the role of the pre-school leader. In: Hirst, K., and Nutbrown, C. (Eds.). Perspectives on Early Childhood Education. Contemporary Research (pp. 13-20). Stoke on Trent: Trentham Books.

DfE. 2012. Statutory Framework for the early Years Foundation Stage. Setting the Standards for Learning, Development and Care for Children from Birth to Five. http://media.education.gov.uk/assets/files/pdf/eyfs\%20statutory\%20framework\%20marc $\underline{\mathrm{h} \% 202012 . \mathrm{pdf}}$ 
DfES. 2003. The future of higher education the Stationery Office Limited Foundation Degree Meeting the need for higher level skills (2003) FDprogress.

PPSPGD10/PUB030191/1003/53 Aim higher DfES

Drury, J., Cocking, C., Beale, J., Hanson, C., and Rapley, F.2005. The phenomenology of empowerment in collective action. British Journal of Social Psychology, Vol. 44, 309328.

Edwards, D. 1997. Discourse and Cognition. London: Sage.

Fleer, M., Anning, A., and Cullen, J. 2009. A framework for conceptualising early childhood education. In: Anning, A., Cullen, J., and Fleer, M (Eds.). Early Childhood Education. Society and Culture (187-204). London: Sage.

Glazzard, J., Chadwick, D., Webster, A., Percival J. 2010. Assessment for Learning in the Early Years Foundation Stage. London: Sage.

Hadfield, M., Jopling, M., Needham, M., Waller, T.,Coleyshaw, L., Mahmoud, E. and Royle, K. 2010. Longitudinal of Early Years Professional Status: an exploration of progress, leadership and impact. Final Report. Research Report DFE-RR239c. Available from: www.wlv.ac.uk/default.aspx?page $=20748$.

Have, P. ten 1999. Doing Conversation Analysis. A Practical Guide. London: Sage.

Hepburn, A., and Wiggins, S. 2007. Discursive research: themes and debates. In: Hepburn, A., and Wiggins, S. (Eds.). Discursive Research in Practice (1-28).

Cambridge: Cambridge University Press.

Heritage, J. and Sefi, S. 1992. Dilemmas of Advice: aspects of the delivery and reception of advice in interactions between Health Visitors and first time mothers. In: Drew, P., and Heritage. (Eds.). Talk at work. Interaction in institutional settings (359417). Cambridge: Cambridge University Press.

Herrera, H., Brown, D., and Portlock, J. 2013. "A case study of the recognition of the Foundation Degree qualification of pharmacy technicians." Journal of Vocational Education \& Training, Vol 65, Issue 1, 127-142.

HM Government. 2012. Opening Doors, Breaking Barriers: A Strategy for Social Mobility. Update on progress since April 2011.

Hughes, M., and Westgate, D. 2004. Teachers and other adults as talk partners for pupils in nursery and reception classes. In: Woodhead, M., Faulkner, D., and Littleton, K. (Eds.). Cultural Worlds of Early Childhood (214-222). London: Routledge. 
Jefferson, G. 1985. An Exercise in the Transcription and Analysis of Laughter. In: Dijk, T.A. van (Ed.), Handbook of Discourse Analysis. Discourse and Dialogue. Volume 3 (2534). London: Academic Press.

Keller, H. 2011. "Autonomy and Relatedness Revisited: Cultural Manifestations of Universal Human Needs" Child Development Perspectives, Volume 6, Issue 1, 12-18.

Kendall, A., Carey, D., and Cramp, A. 2012. "Barriers and solutations to HE progression for Early Years Practitioners." Journal of Vocational Education \& Training, Vol 64, Issues 4, p. 543-560.

Klassen, R.M., and Usher, E.L. 2010. Self-Efficacy in Educational Settings: Recent Research and Emerging Directions. In: Karabenick, S., and Urdan, T.C. (Eds.). Advances in Motivation and Achievement: Decade Ahead, Volume 16A: Theoretical Perspectives on Motivation and Achievement (1-33). Bradford: Emerald Group Publishing Ltd.

Lloyd, E., and Hallet, E. 2010. Professionalising the Early Childhood Workforce in England: work in progress or missed opportunity? Contemporary Issues in Early Childhood, 11(1). 75-88. http://dx.doi.org/10.2304/ciec.2010.11.1.75.

Mahadevan, J. 2011. EYFS has improved childcare in England, Ofsted finds. Children and Young People Now. Retrieved from http://www.cypnow.co.uk/news/1054139/EYFSimproved-childcare-England-Ofsted-finds.

Marsh, H. W. 2007. Self-concept theory, measurement and research into practice: The role of self-concept in educational psychology. Leicester: BPS.

Marsh, H. W., and Martin, A. J. 2011. Academic self-concept and academic achievement: Relations and causal ordering. British Journal of Educational Psychology. Vol. 81, Part 1, 59-77.

Martin, J. 2010. Self-concept as persons' understanding and evaluation of their own actions and experiences: Looking backward and forward from where we are. In: Karabenick, S., and Urdan, T.C. (Eds.). Advances in Motivation and Achievement: Decade Ahead, Volume 16A: Theoretical Perspectives on Motivation and Achievement (167-198). Bradford: Emerald Group Publishing Ltd.

Miller, L. 2008. Developing Professionalism within a regulatory framework in England: Challenges and Possibilities. European Early Childhood Education Research Journal. Vol. 16, No 2, 255-268. 
Miller, P., and Rose, N. 2001.The Tavistock Programme: The Government of Subjectivity and Social Life. In: Wetherell, M., Taylor, S., and Yates, S.J. (Eds.). Discourse Theory and Practice. A Reader (364-379). London: Sage.

Nutbrown, C. 2012. Foundations for Quality. The independent review of early education and childcare qualifications. Final report. Runcan: Department of Education. Available from: www.education.gov.uk/nutbrownreview.

Osgood, J. 2006. A feminist approach to early years professionalism. Early Years. An International Journal of Research and Development. Vol. 26, Number 2, 187-200.

Osgood, J. 2009. Childcare workforce reform in England and the 'early years professional': a critical discourse analysis. Journal of Education Policy. Vol. 24, No. 6, 733-751.

Pomerantz, A. 1986. Extreme case formulations: a new way of legitimating claims. In: Button, G., Drew, P., and Heritage, J. (Eds.). Human Studies. Interaction and language use (Special Issue) Vol. 9, 219-230.

Potter, J. 1997. Discourse analysis as a way of analyzing naturally occurring talk. In: Silverman, D. (Ed.). Qualitative Research: Theory, Method and Practice (144-160). London: Sage.

Potter, J., and Wetherell, M. 1999. Discourse Analysis. In: Smith, J.A., Harre, R., and Van Langenhove, L. (Eds.). Rethinking Methods in Psychology (80-92). London: Sage. Reay, D. (2010). Identity Making in Schools and Classrooms. In: Wetherell, M., and Talpade Mohanty, C. (Eds.).The Sage Handbook of Identities (277-294). London: Sage.

Riley, S.C.E. 2003. "The management of the traditional male role: A discourse analysis of the constructions and functions of provision." Journal of Gender Studies, Vol. 12, 2., 99-113.

Riley, S.C.E. 2008. Identity, community and selfhood: understanding the self in relation to contemporary youth cultures. University of Bath December 2008 unw.beyondcurrenthorizons.org.uk

Scott, P. 1995. The Meanings of Mass Higher Education OUP.

Sims-Schouten, W. 2000. Child care services and parents' attitudes in England, Finland and Greece. In: Pfenning, A., and Bahle, T. (Eds). Family and Family Policies in Europe. Comparative Perspectives (270-288). Frankfurt/Berlin: Peter Lang. 
Sims-Schouten, W., Riley, S. and Willig, C. 2007. Critical Realism in Discourse Analysis: A Presentation of a Systematic Method of analysis Using Women's Talk of Motherhood, Childcare and Female Employment as an Example. Theory \& Psychology. Vol 17, Number 1,101-124.

Sims-Schouten, W and Riley, S.E. 2013, forthcoming. "Employing a form of critical realist discourse analysis for identity research: An example from women's talk of motherhood, childcare and employment" In: Edwards, P., O'Mahoney, J., and Vincent, S. (Eds.).Putting Critical Realism into Practice: A Guide to Research Methods in Organization Studies. Oxford: UOP.

Siraj-Blatchford, I., Sylva, K., Muttock, S., Gilden, R.. and Bell, D. 2002. Researching effective pedagogy in the early years. Norwich: DfES, Queen's Printers.

Siraj-Blatchford, I. 2009. Quality teaching in the early years. In: Anning, A., Cullen, J., and Fleer, M. (Eds). Early Childhood Education. Society and Culture (147-157). London: Sage.

Speer, S. A. and Potter, J. 2000. The management of heterosexist talk: conversational resources and prejudiced claims. Discourse \& Society. Vol 11 (4), 543-572.

Stittrich-Lyons, H. 2007. Professional Development and work-based learning: structured support on an Early Years Foundation degree. Early Years Educator (May 2007).

Sylva, K., Taggart, B., Siraj-Blatchford, I., Totsika, V., Ereky-Stevens, K., Gilden, R., and Bell, D. 2007. Curricular quality and day-to-day learning activities in preschool. International Journal of Early Years Education. 1 (1), 49-65.

Sylva, K., Melhuish, E, Sammons, P., Siraj-Blatchford, I., and Taggart, B. 2010. Early Childhood Matters. Evidence from the Effective Pre-school and Primary Education project. London and New York: Routledge.

Thomasgard, M., Warfield, J., and Williams, R. 2004. Improving Communication between Health and Infant Mental Health Professionals Utilising Ongoing Peer Collaborative Peer Supervision Groups. Infant Mental Health Journal. Vol. 25, Issue 3, 194-218.

Urhahne, D., Chao, S-H., Florineth, M.L., Luttenberger, S., and Paechter, M. 2011. Academic self-concept, learning motivation, and test anxiety of the underestimated student. British Journal of Educational Psychology, Vol. 81, Part 1, 161-177. 
Van IJzendoorn, M. H., Schuengel, C., \& Bakermans-Kranenburg, M. J. 1999.

"Disorganized attachment in early childhood: Meta-analysis of precursors, concomitants, and sequelae." Development and Psychopathology, 11, 225-249.

Wallbank, J.A. 2001. Challenging Motherhood(s). Harlow, England: Prentice Hall.

Weinstein, R.S. 2002. Reaching Higher: The Power of Expectations in Schooling. Cambridge MA, USA: Harvard University Press.

Whalley, M.E. 2008. Leading Practice in Early Years Settings. Exeter: Learningmatter.

Wiggins, S. \& Riley, S. 2010. Discourse Analysis. In, Forrester, M. (Ed). Doing Qualitative Practicals in Psychology: A Student Workbook. London: Sage.

Wright, P. W.G. 1990. Industry and Higher Education Collaboration to improve students' learning and training. Milton Keynes: OUP.

Wright, R.J. 2010. Multifaceted Assessment for Early Childhood Education. London: Sage.

Appendix 1

Transcription Notions

\begin{tabular}{|c|l|}
\hline & Encloses speech that is quieter that the \\
& surrounding talk. \\
\hline$(1.0)$ & Pause length in seconds. \\
\hline$-\quad$ hyphen & Word broken off. \\
\hline$\uparrow$ & Rising intonation. \\
\hline$\downarrow$ & Lowering intonation. \\
\hline CAPITAL LETTERS & Talk that is louder than the surrounding \\
& talk. \\
\hline underline & Stress/emphasis. \\
\hline$><$ & Encloses speeded up talk. \\
\hline
\end{tabular}




\begin{tabular}{|c|l|}
\hline$(\quad)$ & $\begin{array}{l}\text { Encloses words the transcriber is unsure } \\
\text { about. Empty brackets enclose talk that is } \\
\text { not hearable. }\end{array}$ \\
\hline. hhh & In-breath. \\
\hline$[\quad]$ & Overlapping speech. \\
\hline$[\quad$ & Onset of overlapping speech. \\
\hline\{\} & $\begin{array}{l}\text { Clarification, referring to tone or gesture, } \\
\text { e.g. \{laughs\} }\end{array}$ \\
\hline$::$. & Extended sound. \\
\hline$=$ & Marks the immediate 'latching' of \\
& successive talk, whether of one or more \\
& speakers, with no interval. \\
\hline
\end{tabular}

(Edwards, 1997; Jefferson, 1985; Have, 1999) 